\title{
Effects of constant and fluctuating food supply on egg production rates of Acartia grani (Copepoda: Calanoida)
}

\author{
Albert Calbet*, Miquel Alcaraz \\ Institut de Ciències del Mar, CSIC, P. Joan de Borbó S/N, E-08039 Barcelona, Spain
}

\begin{abstract}
The effects of fluctuating food concentration and the influence of temperature and starvation time on egg production rates of the calanold copepod Acartia grani were experimentally determined. Spawning rates oscillated according the frequencies of food fluctuations. For high frequencies of food variability $(12 \mathrm{~h})$, the light conditions at which food was available had a quantitative effect, with higher production rates for copepods feeding at high food concentration by night. Alternating $24 \mathrm{~h}$ high food - low food concentrations had no effects on the average fecundity. However, lower frequency food fluctuations ( $>48 \mathrm{~h}$ high food-low food) reduced egg production. Temperature seemed to control maximum egg production rates, and the length of the starvation period determined the time required to reach normal (control) egg productions after restarting feeding. The tight coupling between food abundance and egg production in $A$. grani (i.e. the incapacity to buffer oscillations in food abundance) is discussed in relation to its domunance in marine areas where the scales of temporal and spatial variability of food abundance allow the species to outcompete other representatives of the same genus.
\end{abstract}

KEY WORDS: Egg production - Food availability Temporal fluctuations C Copepods Acartia grani

\section{INTRODUCTION}

The discontinuous nature of marine phyto- and zooplankton distributions and their temporal variability cover a wide spectrum of scales, which are closely related to similar scales of physical variability (Stommel 1963, Haury et al. 1978, Mackas et al. 1985, Strass 1992). Structure and dynamics of planktonic ecosystems are, in turn, strongly dependent on the coupling between the different trophic components of the system with regard to these spatial and temporal scales of variability (Cushing 1974, Le Fèvre \& Frontier 1988).

For herbivorous zooplankton, food availability depends mainly on the relationships between spatial dimensions of the patchiness field of phyto- and zooplankton, and the organism's mobility. The trophodynamic interactions for plankton take place at fine scale (meters to hundreds of meters, minutes to days; Haury et al. 1978). The fate of zooplankton populations is thus

\footnotetext{
·E-mail: acalbet@icm.csic.es
}

strongly dependent on the modifications induced on growth and production parameters by the time scales (frequency) of alternate periods of feeding and starvation conditions.

Studies on survival during starvation conditions of calanoid copepods indicate specific differences in tolerance of starvation which are inversely related to egg production rates (Dagg 1977), and similar studies dealing with the functional response to fluctuating food conditions (Borchers \& Hutchings 1986, Nival et al. 1990, Davis \& Alatalo 1992) suggest, for some copepod species, the existence of a certain capacity to 'buffer' food variability.

In this work we have tried to evaluate the effects of fluctuating food conditions on calanoid copepods' production at time scales comparable to the 'fine scale' variability in natural systems (Haury et al. 1978).

The species chosen, Acartia grani, is a copepod typical of coastal, semi-confined ecosystems, conditioned by a high degree of instability of physical (temperature and salinity) and biological (food) conditions. 
The 2 goals of the study were: (1) to test the effect on egg production rates and on egg production periodicity of equivalent average food concentrations, either continuously supplied, or fluctuating at different frequencies $(12,24$, and $48 \mathrm{~h}$ ); and (2) to evaluate the effect of the duration of longer starvation periods on the decline and further recovery of egg production rates, and to estimate how these variables are affected by temperature.

\section{MATERIAL AND METHODS}

Experimental organisms. Male and female $1926 \pm 24$ and $1003 \pm 28 \mu \mathrm{m}$ length, respectively) Acartia grani were reared at the laboratory in a temperaturecontrolled room at $18 \pm 1^{\circ} \mathrm{C}$, and fed ad libitum a suspension (5 ppm by volume) of the diatom Thalassiosira weissflogii (13 to $14 \mu \mathrm{m}$ diameter, $1420.3 \pm 3.46 \mu^{3}{ }^{3}$ cell $^{-1}$ ). This diatom was cultured in $\mathrm{f} / 10$ medium (Guillard 1975) at the same temperature as the copepods. The algae were maintained in exponential growth rate in batch cultures in order to avoid changes in their nutritional quality which can affect the production and hatching success of the eggs (Kiørboe 1989, Jónasdóttir 1994). All experiments were conducted in a $12: 12 \mathrm{~h}$ dark/light natural cycle (intensity of light $=50$ to $60 \mu \mathrm{E}$ $\mathrm{m}^{-2} \mathrm{~s}^{-1}$ ).

Effects of fluctuating food availability. The experiments on the effects of different frequencies of fluctuating food concentration were designed in order to provide the copepods with equivalent average amounts of food under 2 conditions: continuous supply at constant concentrations, which were considered the controls, and fluctuating, high food - low food concentrations, simulating the food variability experienced in natural fluctuating systems. The concentrations were chosen in the range in which egg production rates are proportional to the food concentration (Saiz et al. 1992a). The maximum food concentration was always maintained below ingestion rate saturating food concentration for the species (Saiz et al. 1992a).

Recently molted adult Acartia grani were acclimatized to a suspension of $0.9 \mathrm{ppm}$ (by volume) Thalassiosira weissflogii at $18^{\circ} \mathrm{C}$ and $12: 12 \mathrm{~h}$ dark/light natural cycle for 2 d. Six females and 3 males were gently sorted with a wide-mouth pipette and placed in egg-laying chambers. These chambers consisted of 2 concentric perspex cylinders: the inner $15 \mathrm{~cm}$ long, $9 \mathrm{~cm}$ diameter) was covered on the bottom with $200 \mu \mathrm{m}$ nitex mesh, so that copepods were retained and eggs could sink and pass through the bottom mesh to avoid predation. Eggs laid were retained by the outer cylinder $(15 \mathrm{~cm}$ long, $10 \mathrm{~cm}$ diameter $)$, which was covered on the bottom with $40 \mu \mathrm{m}$ nitex mesh.
Egg-laying chambers were suspended in 151 plastic containers ( 6 chambers per container) with filtered sea water and algae at the chosen concentration. In order to avoid algal sedimentation and to secure water flow through the egg-laying chambers, water was circulated with a peristaltic pump at a rate of $0.2 \mathrm{l} \mathrm{h}^{-1}$ in each chamber, equivalent to an exchange rate of more than 6 times a day. Food concentration was monitored by means of a Coulter Multisizer every $6 \mathrm{~h}$, and corrected if necessary. Each day water was changed by a new suspension of Thalassiosira weissflogii at exponential growth rate.

Fluctuations in food concentration were simulated by gently changing the egg-laying chambers from the high food to low food containers and vice versa at the required frequencies, and the eggs laid were collected twice a day (at the end of the $12 \mathrm{~h}$ light and dark periads) and counted under a dissecting microscope. All the experiments were run in triplicale.

For high frequency (12 h fluctuation), 2 controls, with food supplied continuously at 2 constant concentrations and at $12: 12$ h dark/light natural period, simulated the average $(0.9 \mathrm{ppm}$, averaged food) and maximum (1.6 ppm, maximum food) experimental food concentrations. Fluctuating food conditions consisted on $12 \mathrm{~h}$ high food (1.6 ppm) and $12 \mathrm{~h}$ low food (0.2 ppm) supply, combining 2 light situations: high food supplied at night (high food-dark) and high food supplied in daylight (high food-light).

For lower frequency fluctuations, the effects of 2 frequencies of food pulses: $24 \mathrm{~F}$ ( $1 \mathrm{~d}$ high food, $1 \mathrm{~d}$ low food), and 48F ( 2 d high food, 2 d low food) were tested. The experimental design was the same as for $12 \mathrm{~h}$ fluctuation, with the same food concentrations for high food and low food conditions, and a control of $0.9 \mathrm{ppm}$ (average food), equivalent to the average high food - low food concentrations. The light conditions were 12:12 h dark/light natural period. Eggs laid were collected daily at the end of the dark period and counted under a dissecting microscope

Effects of starvation on the decline and recovery of egg production rates. Adult females were acclimatized for $3 \mathrm{~d}$ at $18^{\circ} \mathrm{C}, 12: 12 \mathrm{~h}$ dark/light natural cycle and saturating $(5 \mathrm{ppm})$ food concentration. Five females were placed in $620 \mathrm{ml}$ Pyrex bottles filled with filtered sea water and maintained under starvation conditions for 3, 4 and 5 d respectively (S3, S4 and S5). After the starvation periods, females were fed again with a suspension of $3.5 \mathrm{ppm}$ Thalassiosira weissflogii. Non-starved females, fed continuously $3.5 \mathrm{ppm}$ of the same algae, were used as control. Every day the contents of the control and experimental bottles were filtered through a $20 \mu \mathrm{m}$ mesh submerged sieve to collect eggs. Healthy copepods were placed again in the same bottles with either filtered sea water or food, 
Fig. 1 Egg production corresponding to the short period (12 h) of food fluctuating treatments. (A) Continuous food supply at maximum food concentration. (B) Continuous food supply at average food concentration. (C) 12 h oscillation treatment, high food supplied at night. (D) $12 \mathrm{~h}$ oscillation treatment, high food supplied during the day. Dark zones in abscissae represent time spent in the presence of high food concentration. Vertical shaded areas indicate dark periods. Vertical bars correspond to SE.
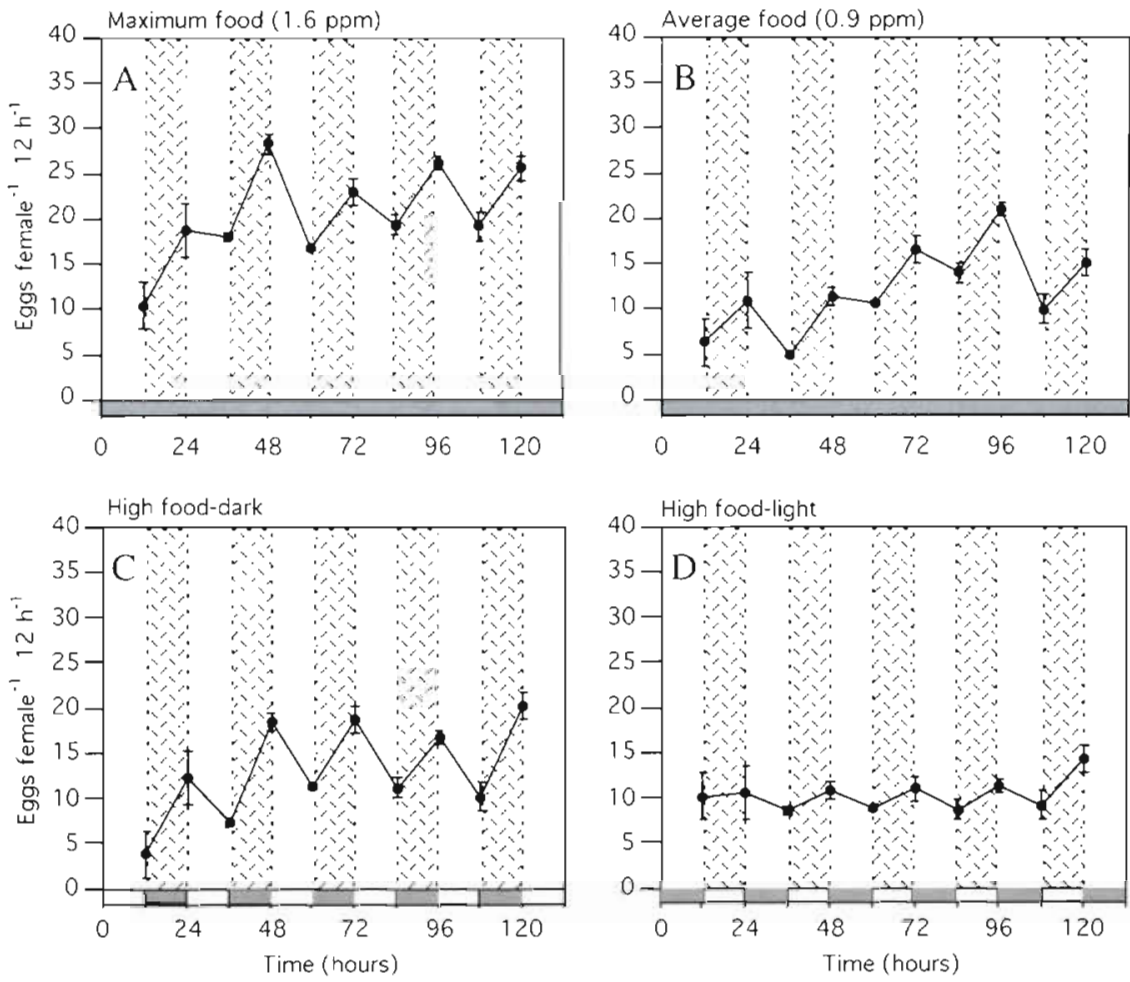

depending on the treatment. Crumpled empty eggs were also included in the counting.

Effects of temperature on the recovery of egg production. In order to study the relationships between temperature and the recovery of egg production rates after a period of starvation, adult males and females were maintained for $2 \mathrm{~d}$ at low food $(0.3 \mathrm{ppm}$ Thalassiosira weissflogii) and $12: 12 \mathrm{~h}$ dark/light natural cycle at 3 temperatures $\left(13,18\right.$ and $23^{\circ} \mathrm{C} ; 4$ replicates per temperature). Five females and 2 males were then picked out and introduced into $650 \mathrm{ml}$ Pyrex bottles and fed again with saturating (3.5 ppm) food, and the egg production was monitored daily for $4 \mathrm{~d}$.

\section{RESULTS}

\section{Effects of fluctuating food concentration on egg production rates}

In the $12 \mathrm{~h}$ fluctuation experiments, egg production resulted in a clearly rhythmical pattern for both continuous (controls) or fluctuating (12 h period) food conditions (Fig. 1), and was significantly higher during the dark hours ( $p<0.001 ; 1$-way ANOVA). This rhythmical pattern in egg production (EP) was maintained even when high food concentration was supplied during daylight hours (high food-light; Fig. 1D). The light con- ditions at which high food conditions occurred also affected egg production (Table 1). The higher values were observed in high food-dark individuals (113 \pm 4 eggs female ${ }^{-1}$, compared to $84 \pm 1$ eggs female ${ }^{-1}$ high food-light, 4 d cumulative EP; $p<0.06$, Tukey's test; Fig 1C)

Table 1. Cumulative egg production (per female during n days) \pm SE for the different food treatments (see text)

\begin{tabular}{|lcc|}
\hline Treatment & $\begin{array}{c}\text { Eggs produced } \\
\text { (cumulative) }\end{array}$ & Days \\
\hline 12 h oscillation & & \\
Average food & $100 \pm 9$ & 4 \\
Maximum food & $171 \pm 9$ & 4 \\
High food-dark & $113 \pm 4$ & 4 \\
High food-light & $84 \pm 1$ & 4 \\
24 to 48 h oscillation & $130 \pm 3$ & \\
Average food & $131 \pm 4$ & 8 \\
$24 \mathrm{~F}$ & $105 \pm 1$ & 8 \\
$48 \mathrm{~F}$ & & \\
Starvation treatment & $291 \pm 25$ & 5 \\
Saturated & $167 \pm 20$ & 5 \\
S3 & $134 \pm 15$ & 5 \\
S4 & $119 \pm 14$ & \\
S5 & & 5 \\
Temperature treatment & $39 \pm 5$ & 5 \\
$13^{\circ} \mathrm{C}$ & $108 \pm 5$ & 5 \\
$18^{\circ} \mathrm{C}$ & $198 \pm 17$ & \\
$23^{\circ} \mathrm{C}$ & & \\
\end{tabular}



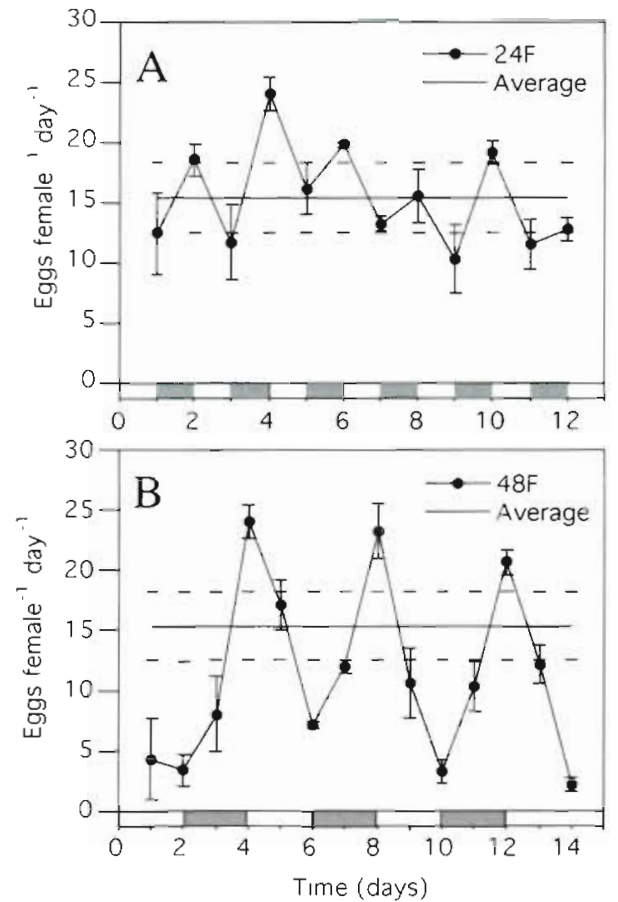

Fig. 2. Temporal pattern of egg production rates as a function of food supply fluctuations. (A) $1 \mathrm{~d}(24 \mathrm{~F})$ fluctuation; (B) $2 \mathrm{~d}$ $(48 \mathrm{~F})$ fluctuation. Horizontal line represents the average egg production for a continuous, average food supply. Honzontal dashed lines are the limits of SE. Dark zones in abscissae represent time spent in high food concentration. Vertical bars correspond to SE

In controls, cumulative egg production was also dependent on food concentration (Fig. 1A, B), with $100 \pm$ 9 eggs female ${ }^{-1}$ at average food conditions, and $171 \pm$ 9 eggs female ${ }^{-1}$ at maximum food conditions (1.6 ppm). Significant differences were found $(p<0.01$; 1 -way ANOVA) between maximum food and the $12 \mathrm{~h}$ fluctuating treatments. All calculations were done excluding the first day due to a possible effect of previous conditions.

Fluctuations of 1 and $2 \mathrm{~d}$ in food concentration ( $24 \mathrm{~F}$ and $48 \mathrm{~F}$ ) significantly affected egg production (Fig. 2A, B), especially at $2 \mathrm{~d}$ frequency $(48 \mathrm{~F})$. The number of eggs laid fluctuated according to the alternating of high food and low food concentration.

No significant differences were observed in the cumulative egg production in $24 \mathrm{~F}(131 \pm 4$ eggs, $8 \mathrm{~d}$ cumulative egg production) as compared with the control (average food, $130 \pm 3$ eggs; Table 1). However, egg production in $48 \mathrm{~F}$ was significantly lower $(105 \pm$ 1 eggs, $\mathrm{p}<0.006$. Tukey's test) than in $24 \mathrm{~F}$ or average food (Table 1)

The oscillations of daily egg production closely followed the fluctuations of food abundance. The average ratio of increase and diminution of daily egg produc-
Table 2. Relative variation of egg production rates (after high food, $1.6 \mathrm{ppm}$ and low food, $0.2 \mathrm{ppm}$ conditions) as compared with constant supply of average food concentration, according to the time scales of food fluctuation $(12,24,48$ and $72 \mathrm{~h})$

\begin{tabular}{|lcc|}
\hline Time scale $(\mathrm{h})$ & High food & Low food \\
\hline 12 & +0.077 & -0.098 \\
24 & +0.125 & -0.226 \\
48 & +0.397 & -0.754 \\
72 & +0.72 & $-1.0^{\mathrm{a}}$ \\
¿Individuals in filtered sea water & \\
\hline
\end{tabular}

tion for the different frequencies of high and low food, respectively, are indicated in Table 2 .

\section{Effects of starvation on egg laying decline and recovery}

The egg production rate decreased considerably after $24 \mathrm{~h}$ starvation and was close to zero after $48 \mathrm{~h}$. Although females resumed spawning after $24 \mathrm{~h}$ from the restart of feeding, the time needed to recover their normal egg production was directly related to the duration of the starvation period (Fig. 3). The duration of the starvation period had a negative effect in cumulative egg production, the number of eggs laid during $5 \mathrm{~d}$ in relation to the days under starvation following a negative exponential function in the range of starvation time considered (Fig. 4).

Temperature had a significant effect on both the maximum egg production rate and the recovery time to achieve maximum egg production rate (Fig. 5). Maximum egg production rates (EPR, eggs female ${ }^{-1} \mathrm{~d}^{-1}$ )

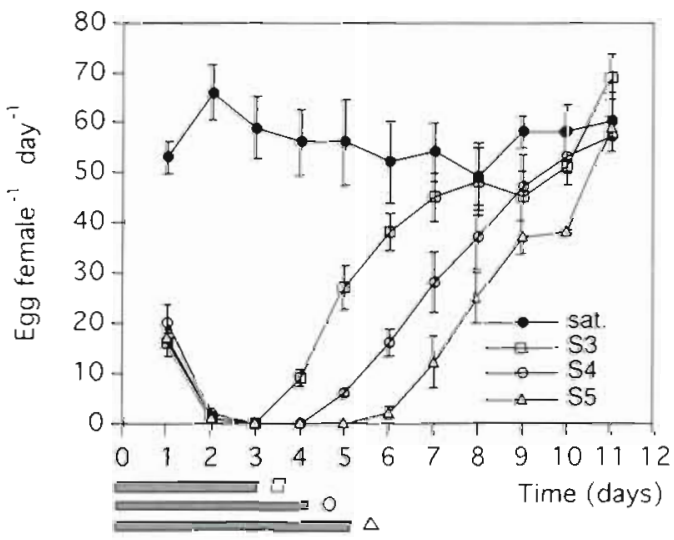

Fig. 3. Time evolution of daily egg production rates under saturating food concentrations after starvation penods of $3 \mathrm{~d}$ (S3), $4 \mathrm{~d}$ (S4) and $5 \mathrm{~d}$ (S5). Control corresponds to the egg production rates for a saturating, continuous food supply (sat.). Honzontal dark bars represent the starvation time for each treatment. Vertical bars correspond to SE 


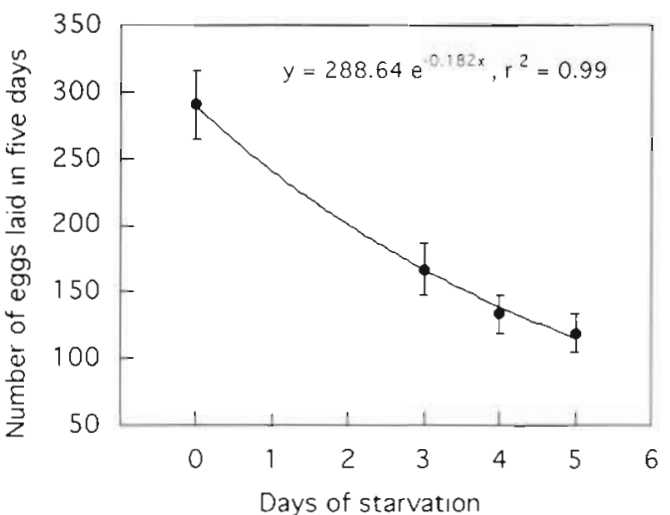

Fig. 4. Exponential relationship between starvation time and cumulative egg production per female after restarting saturating feeding conditions. Vertical bars correspond to SE

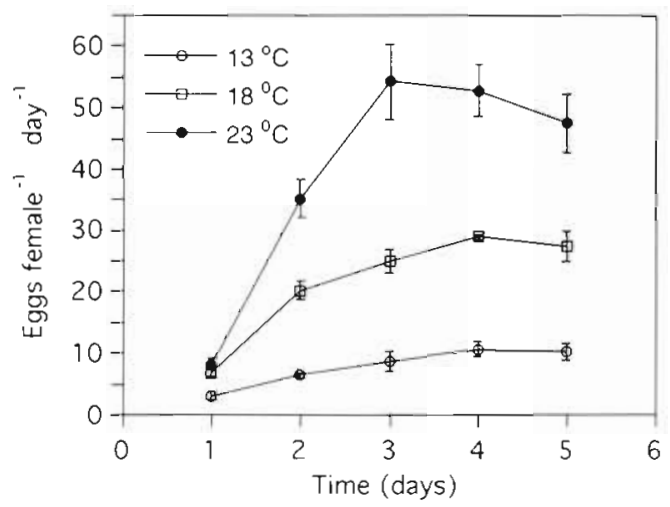

Fig. 5. Time evolution of egg production rates under saturating tood conditions at 13,18 and $23^{\circ} \mathrm{C}$ after 2 d starvation. Abscissae: days after restarting feeding. Vertical bars correspond to $\mathrm{SE}$

were $51 \pm 5$ at $23^{\circ} \mathrm{C}, 28 \pm 1$ at $18^{\circ} \mathrm{C}$ and $10 \pm 1$ at $13^{\circ} \mathrm{C}$ which corresponded to a $\mathrm{Q}_{10}$ value of 3.2 .

Recovery time (time to achieve maximum EPR after the onset of food saturating conditions) ranged from $2 \mathrm{~d}$ at $23^{\circ} \mathrm{C}$ to $3 \mathrm{~d}$ at $18^{\circ} \mathrm{C}$ (Fig. 5). At $13^{\circ} \mathrm{C}$, the time needed to reach maximum egg production is more than $4 \mathrm{~d}$ (maximum egg production rates at this temperature come from authors' unpubl. data). The estimated $Q_{10}$ corresponding to the recovery of egg production is about 2.3 .

\section{DISCUSSION}

For the food concentrations at which experiments were run, egg production rates were linearly related to food concentrations (Saiz et al. 1992a). As a consequence, food fluctuations should have effects on egg production similar to a constant supply of food at average concentration, at least at time scales comparable to the diel activity rhythms of copepods. The diel spawning rhythm, also observed for other copepod species (Marcus 1988), seems to be independent of the feeding conditions. However, when comparing our results with the continuous, non-cycling spawning pattern in Acartia hudsonica under continuous light (Parrish \& Wilson 1978), the light regime could be functionally related to egg-laying cycles. The light conditions in the period at which the algae are available also affect the rates of egg production. Copepods feeding on high food during the night produce more eggs than copepods fed on high food during the day. The differences in egg production in relation to food and light conditions are a consequence of the control exerted by feeding rates on copepod egg production (Kiørboe et al. 1985, Saiz et al. 1992a), and confirm not only the higher nocturnal feeding activity of $A$. grani (Bautista et al. 1988), but the short time (hours) at which female Acartia sp. transform the food ingested into eggs (Tester \& Tester 1990).

The different consequences for egg production derived from the light conditions at which rich-food patches are found by copepods reinforce the importance of match-mismatch mechanisms (Cushing 1974) even at short time scales (hours). Thus, the coupling between copepod diel activity rhythms (feeding, vertical migration), light regime (night-day), and the appropriate environmental trophic conditions (surface or deep phytoplankton rich layers) is of paramount importance from the point of view of plankton dynamics (Saiz \& Alcaraz 1990, Saiz et al. 1992b).

The lack of differences in average egg production between alternating, $24 \mathrm{~h}$ high food - low food supply (24F), and the control (constant supply of average food concentration), were in agreement with the results obtained in the $12 \mathrm{~h}$ fluctuation experiments. However, daily egg production rates fluctuated around the average values according to the alternation of high food low food conditions. At alternating, $2 \mathrm{~d}$ high food - low food concentration (48F), Acartia grani produced less eggs than in the control. This is in agreement with the results obtained by Dagg (1977) with $A$. tonsa, suggesting a low capacity for tolerance of relatively long starvation periods.

Apart from the night-day rhythms in egg production, food fluctuations determine oscillations of egg production rates which are a function of the frequencies at which high food and low food concentrations are supplied. The relative decrease of egg production after low food conditions, as compared to egg production at average, constant food supply, is higher than the corresponding increase after high food conditions, the difference being also a function of the time scale of food 
fluctuations. The consequence is the lower total egg production rates determined by increasing time scale fluctuations of food supply.

The sequence of changes derived from long starvation periods in copepods includes the mobilization of energy reserves (Conover \& Corner 1968, Ikeda 1.974 ) and a decrease in metabolic rates (Conover \& Corner 1968, Mayzaud 1973, 1976. Tsuda 1994), swimming activity (Tiselius 1992), and egg production (Parrish \& Wilson 1978, Checkley 1980, Kiørboe et al. 1985. Hirche 1989). The time required to recover the reserves used during the starvation period, and to resume the normal rate of egg production, seems to be species-specific (Attwood \& Peterson 1989, for Calanus australis; Borchers \& Hutchings 1986 for Calanoides carinatus). In our experiments, the time required to reach the normal (control) egg production in Acartia grani is proportional to the length of the starvation period. However, egg production always starts after $24 \mathrm{~h}$ in the presence of food, although the recovery rate during the first day after the restart of feeding is inversely proportional to the starvation time. This would explain the negative exponential relationship between starvation length and the number of eggs laid in $5 \mathrm{~d}$.

Maximum production rates are strongly dependent on temperature, the corresponding $Q_{10}$ (3.2) coinciding with that observed by Deacon (1980) for ingestion rates by Acartia clausi. However, the time needed to recover maximum egg production rates after starvation appears to be weakly controlled by environmental temperature.

The egg production response of Acartia grani to varying frequencies of food availability, and its capacity to quickly recover from moderate starvation periods, are indicative of a weak capacity to buffer, in terms of fecundity, the changes in food abundance. In the coastal, semi-enclosed habitats usually occupied by the species, high temporal variability and patchiness of phytoplankton, at scales comparable with the experimentally induced fluctuations, are the most characteristic features (Walsh 1976). These are probably environmental conditions which allow $A$. grani to outcompete other congeneric species $(A$. clausi, A. discaudata), thus explaining the niche partitioning of estuarine congeneric associates (Alcaraz 1983, Rodriguez \& Jimenez 1990). The consequences are their segregation according the spatial gradient of environmental variability, or their temporal succession when the gradient in variability is not spatially but temporally forced (Jeffries 1962). Nevertheless, a better understanding of the control exerted by food variability on the dynamics of copepod populations would require further studies about the significance of food fluctuation for the different developmental stages.
Acknowledgements. This work was supported by a Spanish Ministry of Research and Universities grant to A.C. (PN92466513699), the CICYT grant MAR91-0359 to M.A., and the UE MAST-II grant MAS2 CT93-0063. We are grateful to Drs $E$. Salz and X. Irigoien for their advice and critical reading of the manuscript, to $\mathrm{A}$. Cruz for her technical support, and to the staff of the Masnou harbor for their contribution to copepod collection

\section{LITERATURE: CITED}

Alcaraz M (1983) Coexistence and segregation of congenerıc pelagic copepods: spatial distribution of the Acartia complex in the Ria of Vigo (NW of Spain). J Plankton Res 5: $891-900$

Attwood CG, Peterson WT (1989) Reduction in fecundity and lipids of the copepod Calanus australis (Brodskii) by strongly pulsed upwelling. J Exp Mar Bıol Ecol 129: $121-131$

Bautista B, Rodriguez V, Jimenez F (1988) Short-term feeding rates of Acartia grani in natural conditions: diurnal variation. J Plankton Res 1.0:907-920

Borchers P. Hutchings L (1986) Starvation tolerance, development time and egg production of Calanoides carinatus in the Southern Benguela Current. J Plankton Res 8:917-925

Checkley DJ (1980) The egg production of marine planktonic copepods in relation to its food supply: Iaboratory studies. Limnol Oceanogr 25:430-446

Conover RJ, Corner EDS (1968) Respiration and nitrogen excretion by some marine zooplankton in relation to their life cycles. J Mar Biol Ass UK 48:49-75

Cushing DH (1974) The natural regulation of populations. In: Harden Jones FR (ed) Sea fisheries research. Elek Sc1ence, London, p 399-412

Dagg M (1977) Some effects of patchy food environments on copepods. Limnol Oceanogr 22:99-107

Davis CS, Alatalo P (1992) Effects of constant and intermittent food supply on life-history parameters in a marine copepod. Limnol Oceanogr 37:1618-1693

Deacon EE (1980) Grazing of Acartia hudsonica (A. clausi) on Skeletonema costatum in Narragansett Bay (USA): influence of food concentration and temperature. Mar Biol 60: $1.01-113$

Gullard RRL (1975) Culture of phytoplankton for feeding marine invertebrates. In: Smith WL, Chanley MH (eds) Culture of marine invertebrate animals. Plenum Press, New York, p 29-60

Haury LR, McGowan JA, Wiebe PH (1978) Patterns and processes in the time-scales of plankton distributions. In Steele JH (ed) Spatial patterns in plankton communities. Plenum NATO Conferunce Series IV. Marine Sciences 3: $277-327$

Hirche HJ (1989) Egg production of the Arctic copepod Calanus glacialss: laboratory experiments. Mar Biol 103(3): $311-318$

Ikeda T (1974) Nutritional ecology of manne zooplankton Mem Fac Fish Hokkaido Univ 22:1-97

Jeffries HP (1962) Succession of two Acartia species in estuaries. Limnol Oceanogr 9:354-364

Jónasdóttir SH (1994) Effects of food quality on the reproductive success of Acartia tonsa and Acartia hudsonica: laboratory observations. Mar Biol 121:67-81

Kiørboe $\mathrm{T}$ (1989) Phytoplankton growth rate and nitrogen content: implications for feeding and fecundity in a herbivorous copepod. Mar Ecol Prog Ser 55:229-234

Kiorboe T, Møhlenberg F, Hamburger K (1985) Bioenergetics 
of the planktonic copepod Acartia tonsa: relation between feeding, egg production and respiration and composition of specific dynamic action. Mar Ecol Prog Ser 26:85-97

Le Fèvre J, Frontier S (1988) Influence of temporal characteristics of physical phenomena on plankton dynamics, as shown in north-west European marine ecosystems. In: Rothschild BJ (ed) Toward a theory on biological-physical interactions in the world ocean. Kluwer Academic Publishers, Dordrecht, p 245-272

Mackas DL, Denman KL, Abbott MR (1985) Plankton patchlness: biology in the physical vernacular Bull Mar Scl 37. 652-674

Marcus NH (1988) Photoperiodic conditions food patchiness and fecundity. Bull Mar Scj 43\{3\}:641-649

Mayzaud P (1973) Respiration and nitrogen excretıon of zooplankton. II. Studies of the metabolic characteristics of starved animals. Mar Biol 21:19-28

Mayzaud P (1976) Respiration and nitrogen excretion of zooplankton. IV. The influence of starvation on the metabolism and the biochemical composition of some species. Mar Biol 37:47-58

Nival S, Pagano M, Nival P (1990) Laboratory study of the spawning rate of the calanoid copepod Centropages typicus: effect of fluctuatıng food concentration. J Plankton Res 12:535-547

Parrish KK, Wilson DF (1978) Fecundity studies on Acartia tonsa (Copepoda: Calanorda) in standardized culture. Mar Biol 46:65-81

This article was submitted to the editor
Rodriguez $V$, Jimenez F (1990) Co-existence within a group of congeneric species of Acarta (Copepoda Calanoida): sexual dimorphism and ecological niche in Acartia grani. J Plankton Res 12:497-511

Saiz E, Alcaraz M (1990) Pigment gut contents of copepods and deep phytoplankton maximum in the western Mediterranean. J Plankton Res 12(3):665-672

Salz E, Alcaraz M, Paffenhöfer GA (1992a) Effects of smallscale turbulence on feeding rate and gross-growth efficiency of three Acartia species (Copepoda: Calanoida). J Plankton Res 14:1085-1097

Saiz E, Rodriguez V, Alcaraz M (1992b) Spatial distribution and feeding rates of Centropages typicus in relation to frontal hydrographuc structures in the Catalan Sea (western Mediterranean). Mar Biol 112:49-56

Stommel H (1963) Varieties of oceanographic experience. Science 139:572-576

Strass V (1992) Chlorophyll patchiness caused by mesoscale upwelling at fronts. Deep Sea Res 39(1):76-95

Tester PA, Turner JT (1990) How long does it take copepods to make eggs? J Exp Mar Biol Ecol 141:169-182

Tiselius P (1992) Behavior of Acartia tonsa in patchy food environments. Limnol Oceanogr 37:1640-1651

Tsuda A (1994) Starvation tolerance of planktonic marine copepod Pseudocalanus newmani Frost. J Exp Biol Ecol $181: 81-89$

Walsh $J J$ (1976) Herbivory as a factor in patterns of nutrient utulization in the sea. Limnol Oceanogr 21(1):1-13

Manuscript furst received: January 3, 1996

Revised version accepted: April 29, 1996 